\title{
Sleep and Oligodendrocyte Functions
}

\author{
Michele Bellesi
}

Published online: 10 January 2015

(C) Springer International Publishing AG 2015

\begin{abstract}
Transcriptomic studies have revealed that the brains of sleeping and awake animals differ significantly at the molecular level, with hundreds of brain transcripts changing their expression across behavioral states. However, it was unclear how sleep affects specific cell types, such as oligodendrocytes, which make myelin in the healthy brain and in response to injury. In this review, I summarize the recent findings showing that several genes expressed at higher levels during sleep are involved in the synthesis/maintenance of all membranes and of myelin in particular. In addition, I will discuss the effect of sleep and wake on oligodendrocyte precursor cells (OPCs), providing a working hypothesis on the function of REM sleep and acetylcholine in OPC proliferation.
\end{abstract}

Keywords Wake · REM sleep · Sleep deprivation · Bactrap · Myelin · Acetylcholine $\cdot$ Oligodendrocyte precursor cells . Neurogenesis $\cdot$ Multiple sclerosis

\section{Introduction}

Oligodendrocytes together with astrocytes constitute macroglia [1]. The main function of oligodendrocytes is to provide insulation and support for most of the axons in the CNS [2]. A single oligodendrocyte can enwrap around 20 axonal segments on average, providing multiple membrane lamellae in each segment [3]. The maintenance of vast amounts of plasma membrane is metabolically demanding,

This article is part of the Topical Collection on Function of Sleep

M. Bellesi $(\bowtie)$

Department of Psychiatry, University of Wisconsin-Madison, 6001

Research Park Blvd, Madison, WI 53719, USA

e-mail: bellesi@wisc.edu and among all brain cells, oligodendrocytes are the ones showing the highest level of metabolic activity [4].

Myelin production is a key function of oligodendrocytes. Myelin is an insulation material constituted by $80 \%$ lipid and $20 \%$ protein that forms a layer, the myelin sheath, enwrapping the axon [5]. The main function of the myelin sheath is to protect and insulate the axon from the extracellular environment, thus allowing fast impulse propagation along the axon [6].

Sleep is a tightly regulated phenomenon, essential for all animal species carefully studied so far [7], and its loss leads to negative consequences for the brain and the entire body $[8,9]$. Despite the importance of sleep, very little is known about the effect that sleep exerts on oligodendrocytes and myelin production. In the first part of this review, I will summarize the current knowledge on this topic, emphasizing the protective role of sleep on myelination. In the second part, I will provide some insights about the role of sleep on the proliferation of the oligodendrocyte precursor cells (OPCs).

\section{Oligodendrocyte Functions are Modulated by Sleep and Wake}

The first indication that some oligodendrocyte functions were regulated by sleep and wake came from gene expression studies, which showed that the expression of many glial genes was different during sleep and wake [10-17]. In 2004, Cirelli and collaborators found that sleep was associated with the transcription of several genes coding for myelin structural proteins (MOBP, MAG, plasmolipin, CD9), myelin-related receptors (insulin-like growth factor binding protein 2), and enzymes ( $2^{\prime}: 3^{\prime}$-cyclic nucleotide-3'-phosphodiesterase, $\mathrm{Na} / \mathrm{K}$ ATPase subunit $\alpha 2$, methionine adenosyltransferase, carbonic anhydrase II). In addition, they observed a sleep associated increased transcription of genes coding for enzymes involved 
in the synthesis and transport of cholesterol, a major constituent of myelin and other membranes (thiolase, 3-hydroxy-3methylglutaryl-Coenzyme A synthase, squalene synthase, lanosterol $14 \alpha$-demethylase) [11]. Few years later, Mongrain and colleagues also pointed out a similar association between sleep and genes involved in lipid metabolism and myelination. Importantly, to rule out the confounding role of the stress hormone corticosterone during sleep deprivation, they performed gene expression analysis also in adrenalectomized mice in which opalin and plasmolipin, both genes involved in myelination $[18,19]$, were found to be downregulated in sleep deprivation relative to sleep [16]. Another study, aimed to assess the transcriptomic profile of chronic sleep loss, demonstrated that long-term sleep deprivation downregulated the expression of two myelin-related genes, one coding for plasmolipin and the other for CD9, a membrane protein normally expressed in the mature myelin sheath, again suggesting a role for sleep in promoting myelination [13].

However, those gene expression studies had several limitations. First, the gene expression analysis was based on transcripts that were pooled from all brain cells, whereas in situ hybridization experiments have indicated that the effects of sleep and wake can vary significantly depending on cell type [20]. Another limitation was the exclusive assessment of mRNA levels, which are not always predictive of protein levels $[21,22]$. To overcome these limitations, our group recently used the translating ribosome affinity purification (TRAP) technology and microarray analysis to obtain a genome-wide mRNA profiling of oligodendrocytes as a function of sleep, wake, and acute sleep deprivation [23•]. In addition, since the TRAP method targets mRNAs already attached to ribosomes, a more functional (translational) view of cellular function could be achieved [24].

Gene expression analysis performed on oligodendrocyteenriched samples of mouse forebrain showed that the expression of hundreds of transcripts ready to be translated into proteins changes because of sleep and wake in oligodendrocytes, and many wake-related and sleep-related genes have complementary or opposite functions. Specifically, many genes implicated in apoptosis, cellular stress and metabolism were upregulated during wake, whereas genes involved in phospholipids synthesis and myelination were transcribed preferentially during sleep [23], confirming the previous results on whole samples $[11,16]$. Among these, both opalin and plasmolipin showed increased expression. In addition, we found $Q k$, a sleep-related gene coding for the RNA-binding protein Quaking that regulates several myelin-related transcripts at the posttranscriptional level $[25,26]$.

A link between sleep and myelin is consistent also with a recent hypothesis that assigns an energetic role to myelin [27]. Starting from the evidence that several components of the respiratory chains are expressed in myelin [28, 29], Morelli and colleagues proposed that the energy required for the axonal function could be provided by the myelin sheath itself [30]. However, the intense oxidative phosphorylation in the myelin sheaths occurring during wake would lead to a local accumulation of protons. Therefore, during sleep, one of the supposed role of the myelin basic protein (MBP) and phospholipids forming the myelin would be to buffer the protons generated during wake $[27,30]$. The general idea that the oligodendrocytes metabolically support the axons has been confirmed by several lines of evidence [31, 32•]. However, recent data suggest that oligodendrocytes may support axons through mechanisms independent of myelination [33]. Reportedly, the dysmyelinated shiverer mutant mouse, which lacks the myelin basic protein, exhibited no obvious alteration of axonal integrity [34], suggesting that myelination and axonal support are two distinct oligodendrocyte functions. In addition, there is evidence demonstrating that lactate shuttling from the oligodendrocyte to the axon is a key mechanism through which axons are "fed" [33]. In this respect, particular attention has been given to the lactate transporter MCT1 that excretes lactate outside the cell [32] and is highly expressed in oligodendroctyes [35]. Interestingly, Slc16a1, the gene coding for MCT1, was found upregulated in sleep oligodendrocyteenriched samples [23], suggesting that axon refueling might preferably occur in a condition of reduced axonal firing.

In conclusion, all together, these studies indicate that sleep may represent a favorable moment for membrane remodeling and myelination, and, conversely, sleep loss may negatively impact the oligodendrocyte physiology, thereby leading to cell dysfunctions that can undermine the axonal integrity.

\section{OPCs Dynamics in Sleep and Wake}

OPCs represent $\sim 5 \%$ of all cells in the brain [36]; they actively proliferate during development and, albeit at lower rate, during the adult life [36-38]. They mediate myelin formation in healthy brain and are rapidly recruited to prime the recovery process in response to injury [39]. Importantly, recent evidence showed that OPC proliferation is inhibited by extracellular glutamate through AMPA-mediated excitatory currents in OPCs, thus suggesting that neuronal activity can affect myelination and possibly drive other still unknown functions of OPCs [36-38].

Cortical neuronal activity [40], as well the expression of AMPA receptors [40], and their currents [41] increase during wake and decline during sleep. Using in vivo amperometry in the cerebral cortex, a parallel trend of extracellular glutamate levels was observed across the sleep/wake cycle [42], confirming that the glutamatergic tone is higher during wake than during sleep. These findings led us to test the hypothesis that OPCs dynamics could be affected by sleep and wake.

Gene expression analysis performed on oligodendrocyteenriched samples of mouse forebrain showed that many genes 
that changed their expression in sleep and wake were actually $\mathrm{OPC}$ specific genes. A further functional clusterization more focused on OCP genes revealed that genes promoting OPC proliferation were mainly upregulated during sleep [23]. Among these, Yap1, $M x d 3$, and $N r g 2$ have been all linked to OPC proliferation [43-45]. By contrast, genes mostly involved in OPC differentiation and apoptosis were preferably transcribed during wake [23]. It is worth noting that $Y Y 1$ and Sox 17 are wake genes, and both implicated in OPC maturation, as it has been shown that interfering with their expression arrests the OPC differentiation towards more mature stages $[46,47]$.

Additional assessments based on immunocytochemical OPC characterization in combination with the BrdU assay, a specific method to evaluate cell proliferation, demonstrated that the number of newly formed OPCs increased during sleep relative to spontaneous wake and sleep deprivation. Finally, EEG studies in conjunction with BrdU assessments revealed a positive correlation between the level of OPC proliferation and the amount of REM sleep, indicating that this stage of sleep could represent a favorable condition for OPC proliferation [23].

\section{Is REM Sleep Regenerative for OPCs?}

The idea that sleep may promote cell proliferation is not new. Most of the studies have focused on understanding how sleep regulates hippocampal neurogenesis in adult mammals [48-57]. In a recent review, Mueller and colleagues concluded that much of the evidence supports the idea that sleep disruption has a negative impact on cell proliferation and, specifically, on neurogenesis [58]. The mechanisms by which this occurs are not clear, but there are indications that some "wake" factors, including corticosterone and interleukin $1 \beta$, may mediate this effect $[51,59]$. This would suggest that the presence of these factors is likely to be detrimental for neurogenesis and, eventually, for cell proliferation in general, weighing against the hypothesis that favoring neurogenesis is a function of sleep [58].

However, several studies showed that this might not be the case for REM sleep, which may have a more active role. A recent work performed using a selective REM sleep deprivation apparatus capable of producing an arousal stimulus as soon as some EEG features for REM sleep were met found a $63 \%$ reduction in cell proliferation in the dentate gyrus [60]. The rate of proliferation also correlated with the amount of time spent by the mice in REM sleep [60]. In another study, $72 \mathrm{~h}$ of REM sleep deprivation led to a delayed rebound in neurogenesis 1 week after the deprivation; importantly, this increase was present also in adrenalectomized mice [51]. Since REM sleep rebound can persist for weeks after longterm REM deprivation [61], it is possible that the observed increase in REM sleep had a positive modulation on neurogenesis, independent of corticosterone.

REM sleep is characterized by rapid and random movements of the eyes, muscle atonia, and high-frequency lowvoltage EEG [62]. From a neurochemical point of view, REM sleep is characterized by low levels of neuromodulators with the exception of acetylcholine (Ach), whereas in NREM sleep, Ach is also low [63, 64]. Therefore, if some positive functions on cell proliferation are associated with REM sleep, Ach itself might carry them out.

Indeed, there are several lines of evidence indicating that Ach regulates neurogenesis in the hippocampus (see [65 ${ }^{\circ}$ for a review). Immunotoxic ablation of basal forebrain cholinergic neurons projecting to the hippocampus strongly reduces the number of proliferating BrdU immunoreactive cells in the dentate gyrus [66]. Moreover, transgenic mice overexpressing a recombinantly inactivated form of synaptic Ach-esterase showed significantly reduced Ach hydrolysis and enhanced proliferation of progenitor cells, suggesting that Ach and Achesterase are important regulators of proliferative activity [67]. These results have been confirmed also in a recent experiment performed in vitro, in which a potent effect of Ach on neuroblast production has been discovered from postnatal sub-ventricular zone (SVZ), another region of the forebrain where neurogenesis occurs in addition to the dentate gyrus [68•]. Furthermore, the same study found a previously unknown population of choline acetyltransferase $(\mathrm{ChAT})(+)$ neurons, which provide innervation of the SVZ and release Ach locally in an activity-dependent manner. Optogenetic inhibition and stimulation of these cells in vivo showed that they were capable of controlling neurogenic proliferation in SVZ [68].

SVZ is a critical region also for OPCs proliferation [36, 38, 69]. In addition, several in vitro studies demonstrated the Ach favors not only neurogenesis but also OPCs proliferation and survival $[70,71,72 \cdot, 73,74]$. Exposure of primary OPC cultures to Ach led to an augmented OPC proliferation via the activation of Ach M1, M3, and M4 muscarinic receptors on OPCs [72•]. Since muscarinic receptors on OPCs are developmentally regulated, being highly expressed mainly in immature cells, Ach may contribute to the maintenance of an immature proliferating OPC pool in the brain [72]. Other findings, in addition to support the role of Ach as a growth regulatory signal for OPC proliferation, identified the molecular pathway that mediates this effect, which involves the protein kinase $\mathrm{C}$ activation and MAPK phosphorylation [70, 73].

In conclusion, these studies support the hypothesis that REM sleep may exert a positive modulation on OPC proliferation in forebrain, likely through the action of Ach (Fig. 1). However, many steps of this process need further testing. For example, the notion that Ach induces OPC proliferation is only supported by in vitro studies. In addition, it is still unclear 
a

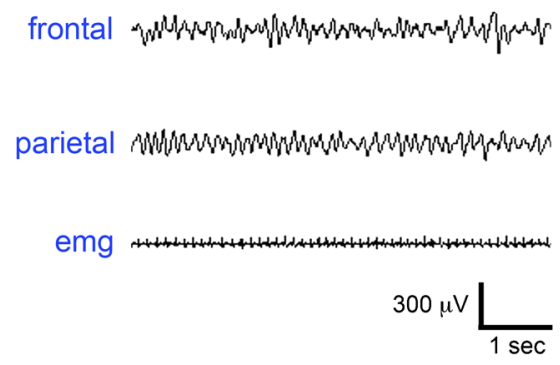

b

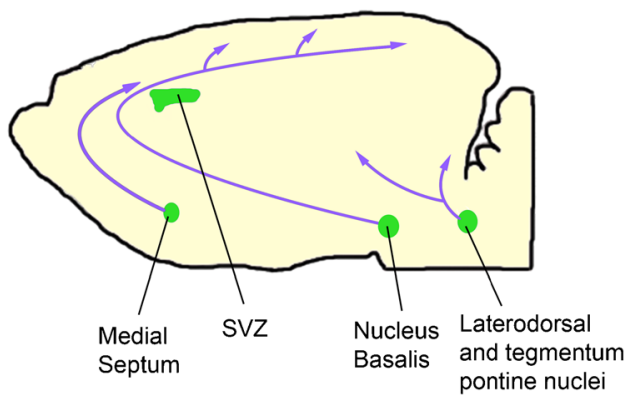

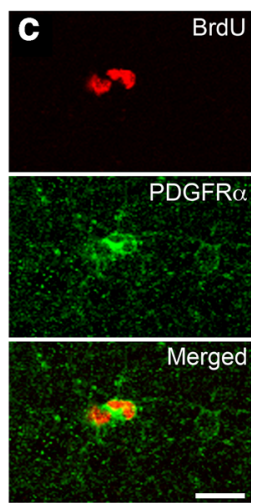

Fig. 1 Key elements of the hypothetical mechanism leading to OPC proliferation, which involves REM sleep and acetylcholine release. a Example of REM sleep as it appears in the mouse EEG. Note the intense theta activity in frontal and parietal derivations associated with muscle atonia (EMG, electromyogram). b Schematic section of a mouse brain, showing the locations of the most important groups of acetylcholine neurons and their projections to the forebrain.

why during wake, a state in which the Ach tone is elevated as much as REM sleep, OPC proliferation seems to be inhibited. In vitro experiments have indicated that the presence of noradrenaline, the other major wake neuromodulator, may induce cytotoxicity and even apoptosis in OPCs through oxidative stress [75]. If these results were confirmed in vivo, during wake, the positive action of Ach on OPC proliferation could not take place because of the counteracting action of noradrenaline.

\section{Oligodendrocytes and OPCs Pathology and Sleep}

If sleep plays a role in supporting some important oligodendrocyte functions, like myelination, and exerts a promoting role in the proliferation of new immature oligodendrocytes, then it is natural to ask whether sleep could be protective in diseases characterized by oligodendrocyte dysfunction. Unfortunately, there is not yet a definitive answer to this question. For instance, patients affected by obstructive sleep apnea show white matter alterations [76-78]. Although intermittent hypoxia has likely a major role in this case [79], sleep fragmentation associated with this disease can be also important and can negatively impact the oligodendrocyte physiology. Along the same line, a recent postmortem study revealed decreased myelination in patients suffering from restless leg syndrome [80], a disease often associated with insufficient sleep [81]. Although a direct demonstration that chronic sleep restriction can lead to oligodendrocyte dysfunction and myelin alteration is still lacking, these studies suggest that sleep loss may be detrimental to oligodendrocytes and more specifically to myelin. In multiple sclerosis (MS), an inflammatory autoimmune disease characterized by CNS demyelinization, sleep disturbances are occurring in roughly $50 \%$ of the
SubVentricular Zone (SVZ) was included among the cholinergic areas, because it displays locally cholinergic innervation. c Example of proliferating OPCs stained with the specific OPC marker PDGFR $\alpha$ (green) and positive to bromodeoxyuridine (BrdU, red), a synthetic nucleoside commonly used in the detection of proliferating cells in living tissues. Scale bar: $15 \mu \mathrm{m}$

patients [82-85]. However, it is unknown whether sleep problems are only a consequence of the illness or if they actively contribute to the progress of the disease. Clinical studies have reported that sleep problems in MS are often under diagnosed [86] and may be related to daytime fatigue experienced by most of the patients [87]. There is also some evidence showing a positive correlation between the severity of the clinical picture and the presence of sleep problems [83], suggesting that the correction of sleep problems might help to improve the clinical conditions of MS patients. However, if this beneficial role of sleep is mediated by the mechanisms previously described on myelin and OPC proliferation remains unclear and needs further investigations.

\section{Compliance with Ethics Guidelines}

Conflict of Interest Michele Bellesi declares that he has no conflict of interest.

Human and Animal Rights and Informed Consent This article does not contain any studies with human or animal subjects performed by any of the authors.

\section{References}

Papers of particular interest, published recently, have been highlighted as:

- Of importance

1. Baumann N, Pham-Dinh D. Biology of oligodendrocyte and myelin in the mammalian central nervous system. Physiol Rev. 2001;81: 871-927.

2. Armati P, Mathey E. The biology of oligodendrocytes. Cambridge University Press; 2010 
3. Basic neurochemistry. 6th ed. Lippincott-Raven; 1999

4. Richter-Landsberg C. The oligodendroglia cytoskeleton in health and disease. J Neurosci Res. 2000;59:11-8.

5. Aggarwal S, Yurlova L, Simons M. Central nervous system myelin: structure, synthesis and assembly. Trends Cell Biol. 2011;21:58593.

6. Sherman DL, Brophy PJ. Mechanisms of axon ensheathment and myelin growth. Nat Rev Neurosci. 2005;6:683-90.

7. Cirelli C, Tononi G. Is sleep essential? PLoS Biol. 2008;6:e216.

8. Borbély AA, Achermann P. Sleep homeostasis and models of sleep regulation. J Biol Rhythm. 1999;14:557-68.

9. Tononi G, Cirelli C. Sleep and the price of plasticity: from synaptic and cellular homeostasis to memory consolidation and integration. Neuron. 2014;81:12-34.

10. Cirelli C, Tononi G. Gene expression in the brain across the sleepwaking cycle. Brain Res. 2000;885:303-21.

11. Cirelli C, Gutierrez CM, Tononi G. Extensive and divergent effects of sleep and wakefulness on brain gene expression. Neuron. 2004;41:35-43.

12. Cirelli C, LaVaute TM, Tononi G. Sleep and wakefulness modulate gene expression in drosophila. J Neurochem. 2005;94:1411-9.

13. Cirelli C, Faraguna U, Tononi G. Changes in brain gene expression after long-term sleep deprivation. J Neurochem. 2006;98:1632-45.

14. Terao A, Wisor JP, Peyron C, Apte-Deshpande A, Wurts SW, Edgar $\mathrm{DM}$, et al. Gene expression in the rat brain during sleep deprivation and recovery sleep: an affymetrix GeneChip ${ }^{\circledR}$ study. Neuroscience. 2006;137:593-605.

15. Maret S, Dorsaz S, Gurcel L, Pradervand S, Petit B, Pfister C, et al. Homerla is a core brain molecular correlate of sleep loss. Proc Natl Acad Sci. 2007;104:20090-5.

16. Mongrain V, Hernandez SA, Pradervand S, Dorsaz S, Curie T, Hagiwara G, et al. Separating the contribution of glucocorticoids and wakefulness to the molecular and electrophysiological correlates of sleep homeostasis. Sleep. 2010;33:1147-57.

17. Vecsey CG, Peixoto L, Choi JHK, Wimmer M, Jaganath D, Hernandez PJ, et al. Genomic analysis of sleep deprivation reveals translational regulation in the hippocampus. Physiol Genomics. 2012;44:981-91.

18. Yoshikawa F, Sato Y, Tohyama K, Akagi T, Hashikawa T, Nagakura-Takagi $Y$, et al. Opalin, a transmembrane sialylglycoprotein located in the central nervous system myelin paranodal loop membrane. J Biol Chem. 2008;283:20830-40.

19. Cochary EF, Bizzozero OA, Sapirstein VS, Nolan CE, Fischer I. Presence of the plasma membrane proteolipid (plasmolipin) in myelin. J Neurochem. 1990;55:602-10.

20. Thompson CL, Wisor JP, Lee C-K, Pathak SD, Gerashchenko D, Smith KA, et al. Molecular and anatomical signatures of sleep deprivation in the mouse brain. Neurogenomics. 2010;4:165.

21. Waters KM, Pounds JG, Thrall BD. Data merging for integrated microarray and proteomic analysis. Brief Funct Genomic Proteomics. 2006;5:261-72.

22. Bitton DA, Okoniewski MJ, Connolly Y, Miller CJ. Exon level integration of proteomics and microarray data. BMC Bioinforma. 2008;9:118.

23. Bellesi M, Pfister-Genskow M, Maret S, Keles S, Tononi G, Cirelli C. Effects of sleep and wake on oligodendrocytes and their precursors. J Neurosci. 2013;33:14288-300. Most recent findings about the effects of sleep and wake on gene expression in oligodendrocytes. They include also experiments showing that the rate of growth of oligodendrocyte precursor cells doubles during sleep, and the cell production increases particularly in REM sleep.

24. Doyle JP, Dougherty JD, Heiman M, Schmidt EF, Stevens TR, Ma $\mathrm{G}$, et al. Application of a translational profiling approach for the comparative analysis of CNS cell types. Cell. 2008;135:749-62.
25. Zearfoss NR, Farley BM, Ryder SP. Post-transcriptional regulation of myelin formation. Biochim, Biophys Acta BBA - Gene Regul Mech. 2008;1779:486-94.

26. Zhao L, Mandler MD, Yi H, Feng Y. Quaking I controls a unique cytoplasmic pathway that regulates alternative splicing of myelinassociated glycoprotein. Proc Natl Acad Sci. 2010;107:19061-6.

27. Morelli A, Ravera S, Panfoli I. Myelin sheath: a new possible role in sleep mechanism. Sleep Med. 2011;12:199.

28. Yamaguchi Y, Miyagi Y, Baba H. Two-dimensional electrophoresis with cationic detergents: a powerful tool for the proteomic analysis of myelin proteins. Part 2: analytical aspects. J Neurosci Res. 2008;86:766-75.

29. Taylor CM, Marta CB, Claycomb RJ, Han DK, Rasband MN, Coetzee T, et al. Proteomic mapping provides powerful insights into functional myelin biology. Proc Natl Acad Sci U S A. 2004;101: 4643-8.

30. Morelli A, Ravera S, Panfoli I. Hypothesis of an energetic function for myelin. Cell Biochem Biophys. 2011;61:179-87.

31. Fünfschilling U, Supplie LM, Mahad D, Boretius S, Saab AS, Edgar $\mathrm{J}$, et al. Glycolytic oligodendrocytes maintain myelin and long-term axonal integrity. Nature. 2012;485:517-21.

32. Lee Y, Morrison BM, Li Y, Lengacher S, Farah MH, Hoffman PN, et al. Oligodendroglia metabolically support axons and contribute to neurodegeneration. Nature. 2012;487:443-8. Disruption of the lactate transporter monocarboxylate transporter 1 , which is enriched in oligodendrocytes and reduced in patients with amyotrophic lateral sclerosis, leads to in vitro and in vivo axon damage and neurodegeneration.

33. Saab AS, Tzvetanova ID, Nave K-A. The role of myelin and oligodendrocytes in axonal energy metabolism. Curr Opin Neurobiol. 2013;23:1065-72.

34. Griffiths I, Klugmann M, Anderson T, Yool D, Thomson C, Schwab $\mathrm{MH}$, et al. Axonal swellings and degeneration in mice lacking the major proteolipid of myelin. Science. 1998;280:1610-3.

35. Rinholm JE, Hamilton NB, Kessaris N, Richardson WD, Bergersen LH, Attwell D. Regulation of oligodendrocyte development and myelination by glucose and lactate. J Neurosci. 2011;31:538-48.

36. Richardson WD, Young KM, Tripathi RB, McKenzie I. NG2-glia as multipotent neural stem cells - fact or fantasy? Neuron. 2011;70: 661-73.

37. Mangin J-M, Gallo V. The curious case of NG2 cells: transient trend or game changer? ASN Neuro. 2011;3:AN20110001

38. Nishiyama A, Komitova M, Suzuki R, Zhu X. Polydendrocytes (NG2 cells): multifunctional cells with lineage plasticity. Nat Rev Neurosci. 2009;10:9-22.

39. Levine JM, Reynolds R, Fawcett JW. The oligodendrocyte precursor cell in health and disease. Trends Neurosci. 2001;24:39-47.

40. Vyazovskiy VV, Olcese U, Lazimy YM, Faraguna U, Esser SK, Williams JC, et al. Cortical firing and sleep homeostasis. Neuron. 2009;63:865-78

41. Lanté F, Toledo-Salas J-C, Ondrejcak T, Rowan MJ, Ulrich D. Removal of synaptic $\mathrm{Ca}^{2+}$-permeable AMPA receptors during sleep. J Neurosci. 2011;31:3953-61.

42. Dash MB, Douglas CL, Vyazovskiy VV, Cirelli C, Tononi G. Longterm homeostasis of extracellular glutamate in the rat cerebral cortex across sleep and waking states. J Neurosci. 2009;29:620-9.

43. Barisone GA, Yun J-S, Díaz E. From cerebellar proliferation to tumorigenesis: new insights into the role of Mad3. Cell Cycle. 2008;7:423-7.

44. Canoll PD, Musacchio JM, Hardy R, Reynolds R, Marchionni MA, Salzer JL. GGF/neuregulin is a neuronal signal that promotes the proliferation and survival and inhibits the differentiation of oligodendrocyte progenitors. Neuron. 1996;17:229-43.

45. Fernandez-L A, Northcott PA, Dalton J, Fraga C, Ellison D, Angers $\mathrm{S}$, et al. YAP1 is amplified and up-regulated in hedgehog-associated 
medulloblastomas and mediates sonic hedgehog-driven neural precursor proliferation. Genes Dev. 2009;23:2729-41.

46. Sohn J, Natale J, Chew L-J, Belachew S, Cheng Y, Aguirre A, et al. Identification of Sox17 as a transcription factor that regulates oligodendrocyte development. J Neurosci. 2006;26:9722-35.

47. He Y, Dupree J, Wang J, Sandoval J, Li J, Liu H, et al. The transcription factor Yin Yang1 is essential for oligodendrocyte progenitor differentiation. Neuron. 2007;55:217-30.

48. Grassi Zucconi G, Cipriani S, Balgkouranidou I, Scattoni R. "One night" sleep deprivation stimulates hippocampal neurogenesis. Brain Res Bull. 2006;69:375-81.

49. Guzman-Marin R, Bashir T, Suntsova N, Szymusiak R, McGinty D. Hippocampal neurogenesis is reduced by sleep fragmentation in the adult rat. Neuroscience. 2007;148:325-33.

50. Hairston IS, Little MTM, Scanlon MD, Barakat MT, Palmer TD, Sapolsky RM, et al. Sleep restriction suppresses neurogenesis induced by hippocampus-dependent learning. J Neurophysiol. 2005;94:4224-33.

51. Mirescu C, Gould E. Stress and adult neurogenesis. Hippocampus. 2006;16:233-8.

52. Guzmán-Marín R, Suntsova N, Stewart DR, Gong H, Szymusiak R, McGinty D. Sleep deprivation reduces proliferation of cells in the dentate gyrus of the hippocampus in rats. J Physiol. 2003;549:56371.

53. Junek A, Rusak B, Semba K. Short-term sleep deprivation may alter the dynamics of hippocampal cell proliferation in adult rats. Neuroscience. 2010;170:1140-52.

54. Tung A, Takase L, Fornal C, Jacobs B. Effects of sleep deprivation and recovery sleep upon cell proliferation in adult rat dentate gyrus. Neuroscience. 2005;134:721-3.

55. García-García F, De la Herrán-Arita AK, Juárez-Aguilar E, Regalado-Santiago C, Millán-Aldaco D, Blanco-Centurión C, et al. Growth hormone improves hippocampal adult cell survival and counteracts the inhibitory effect of prolonged sleep deprivation on cell proliferation. Brain Res Bull. 2011;84:252-7.

56. Roman V, Van der Borght K, Leemburg SA, Van der Zee EA, Meerlo P. Sleep restriction by forced activity reduces hippocampal cell proliferation. Brain Res. 2005;1065:53-9.

57. Van der Borght K, Ferrari F, Klauke K, Roman V, Havekes R, Sgoifo A, et al. Hippocampal cell proliferation across the day: increase by running wheel activity, but no effect of sleep and wakefulness. Behav Brain Res. 2006;167:36-41.

58. Mueller AD, Meerlo P, McGinty D, Mistlberger RE. Sleep and adult neurogenesis: implications for cognition and mood. Springer Berlin Heidelberg; 2013 [cited 2014 Dec 12]. p. 1-31. Available from: http://link.springer.com/chapter/10.1007/7854_2013_251

59. Koo JW, Duman RS. IL- $1 \beta$ is an essential mediator of the antineurogenic and anhedonic effects of stress. Proc Natl Acad Sci. 2008;105:751-6.

60. Guzman-Marin R, Suntsova N, Bashir T, Nienhuis R, Szymusiak R, McGinty D. Rapid eye movement sleep deprivation contributes to reduction of neurogenesis in the hippocampal dentate gyrus of the adult rat. Sleep. 2008;31:167-75.

61. Everson CA, Gilliland MA, Kushida CA, Pilcher JJ, Fang VS, Refetoff S, et al. Sleep deprivation in the rat: IX. Recovery Sleep. 1989;12:60-7.

62. Strohl KP. BN Mallick, SR Pandi-Perumal, RW McCarley, AR. Morrison (eds): Rapid eye movement sleep: regulation and function (hardback). Sleep Breath. 2012;16:969-70

63. Neurochemistry of sleep and wakefulness | Neuroscience [Internet]. Camb. Univ. Press. [cited 2014 Dec 12]. Available from: http:// www.cambridge.org/us/academic/subjects/life-sciences/ neuroscience/neurochemistry-sleep-and-wakefulness

64. Stenberg D. Neuroanatomy and neurochemistry of sleep. Cell Mol Life Sci. 2007;64:1187-204.
65. Bruel-Jungerman E, Lucassen PJ, Francis F. Cholinergic influences on cortical development and adult neurogenesis. Behav Brain Res. 2011;221:379-88. Recent review discussing the mechanisms by which acetylcholine promotes hippocampal neurogenesis.

66. Mohapel P, Leanza G, Kokaia M, Lindvall O. Forebrain acetylcholine regulates adult hippocampal neurogenesis and learning. Neurobiol Aging. 2005;26:939-46.

67. Cohen JE, Zimmerman G, Melamed-Book N, Friedman A, Dori A, Soreq H. Transgenic inactivation of acetylcholinesterase impairs homeostasis in mouse hippocampal granule cells. Hippocampus. 2008;18:182-92.

68. Paez-Gonzalez P, Asrican B, Rodriguez E, Kuo CT. Identification of distinct ChAT + neurons and activity-dependent control of postnatal SVZ neurogenesis. Nat Neurosci. 2014;17:934-42. The proliferation of newborn neurons is controlled by a set of previously unknown neurons expressing choline acetyltransferase in the adult SVZ. This is the first proof of a mechanism connecting brain activity to neurogenesis in the adult mammalian brain.

69. Agathou S, Karadottir RT, Kazanis I. Niche derived oligodendrocyte progenitors: a source of rejuvenation or complementation for local oligodendrogenesis? Front Cell Neurosci. 2013;7:188.

70. Ma W, Maric D, Li B, Hu Q, Andreadis JD, Grant GM, et al. Acetylcholine stimulates cortical precursor cell proliferation in vitro via muscarinic receptor activation and MAP kinase phosphorylation. Eur J Neurosci. 2000;12:1227-40.

71. Zhou C, Wen Z, Shi D, Xie Z. Muscarinic acetylcholine receptors involved in the regulation of neural stem cell proliferation and differentiation in vitro. Cell Biol Int. 2004;28:63-7.

72. De Angelis F, Bernardo A, Magnaghi V, Minghetti L, Tata AM. Muscarinic receptor subtypes as potential targets to modulate oligodendrocyte progenitor survival, proliferation, and differentiation. Dev Neurobiol. 2012;72:713-28. Most recent findings on the role of Acetylcholine in promoting oligodendrocyte precursor cell proliferation via the activation of M1, M3, M4 muscarinic receptors.

73. Larocca JN, Almazan G. Acetylcholine agonists stimulate mitogenactivated protein kinase in oligodendrocyte progenitors by muscarinic receptors. J Neurosci Res. 1997;50:743-54.

74. Ragheb F, Molina-Holgado E, Cui Q-L, Khorchid A, Liu H-N, Larocca JN, et al. Pharmacological and functional characterization of muscarinic receptor subtypes in developing oligodendrocytes. J Neurochem. 2001;77:1396-406.

75. Khorchid A, Fragoso G, Shore G, Almazan G. Catecholamineinduced oligodendrocyte cell death in culture is developmentally regulated and involves free radical generation and differential activation of caspase-3. Glia. 2002;40:283-99.

76. Kumar R, Pham TT, Macey PM, Woo MA, Yan-Go FL, Harper RM. Abnormal myelin and axonal integrity in recently diagnosed patients with obstructive sleep apnea. Sleep. 2014;37:723-32.

77. Macey PM, Kumar R, Woo MA, Valladares EM, Yan-Go FL, Harper RM. Brain structural changes in obstructive sleep apnea. Sleep. 2008;31:967-77.

78. Kumar R, Chavez AS, Macey PM, Woo MA, Yan-Go FL, Harper RM. Altered global and regional brain mean diffusivity in patients with obstructive sleep apnea. J Neurosci Res. 2012;90:2043-52.

79. Veasey SC, Lear J, Zhu Y, Grinspan JB, Hare DJ, Wang S, et al. Long-term intermittent hypoxia elevates cobalt levels in the brain and injures white matter in adult mice. Sleep. 2013;36:1471-81.

80. Connor JR, Ponnuru P, Lee B-Y, Podskalny GD, Alam S, Allen RP, et al. Postmortem and imaging based analyses reveal CNS decreased myelination in restless legs syndrome. Sleep Med. 2011;12:614-9.

81. Montplaisir J, Allen RP, Walters AS, Ferini-Strambi L. Restless legs syndrome and periodic limb movements during sleep. Princ Pract Sleep Med. 2005;4:839-52.

82. Caminero A, Bartolomé M. Sleep disturbances in multiple sclerosis. J Neurol Sci. 2011;309:86-91. 
83. Leonavicius R, Adomaitiene V. Features of sleep disturbances in multiple sclerosis patients. Psychiatr Danub. 2014;26:249-55.

84. Tachibana N, Howard RS, Hirsch NP, Miller DH, Moseley IF, Fish D. Sleep problems in multiple sclerosis. Eur Neurol. 1994;34:320-3.

85. Lunde HMB, Bjorvatn B, Myhr K-M, Bø L. Clinical assessment and management of sleep disorders in multiple sclerosis: a literature review. Acta Neurol Scand. 2013;127:24-30.
86. Brass SD, Li C-S, Auerbach S. The underdiagnosis of sleep disorders in patients with multiple sclerosis. J Clin Sleep Med JCSM Off Publ Am Acad Sleep Med. 2014;10:1025-31.

87. Veauthier C, Gaede G, Radbruch H, Gottschalk S, Wernecke K-D, Paul F. Treatment of sleep disorders may improve fatigue in multiple sclerosis. Clin Neurol Neurosurg. 2013;115: $1826-30$. 